\section{HIV/TB co-infections rising}

Y ou've got roo-year-old TB married to 25 -year-old HIV and the honeymoon is causing havoc."

That's how Kenyan activist Lucy Chesire described the impact when people are infected with both mycobacterium tuberculosis and the human immunodeficiency virus.

Tuberculosis, a preventable and treatable disease, is now the leading cause of death for people infected with HIV.

While the incidence of TB is declining in most of the world, there has been a $4 \%$ to $5 \%$ annual increase in Africa in recent years, Dr. Paul Nunn of the World Health Organization told the XVIth International AIDS conference in Toronto in mid-August. And the appearance of multidrug-resistant TB is causing alarm in public health circles.

About one-third of people infected with HIV are also infected with the tuberculosis bacillus, and the latter causes the deaths, each year, of a quarter of a million people living with HIV, said Dr. Helene Gayle, president of the International AIDS Society.

TB is "a direct threat to the scaleup of access to HIV treatment," said Dr. Kevin De Cock, head of the WHO program for HIV/AIDS. That scale-up, agreed to by members of the G8 nations last year, aims to provide nearuniversal access to antiretroviral (ARV) treatment for HIV by 20Io. Currently, about $\mathrm{I} .3$ million people in the developing world have access to ARV treatment, while an estimated 5 million in need do not have access. An estimated 40 million people now live with HIV.

But De Cock warned that TB may be the "Achilles heel" of such a scale-up, and the spectre of multidrug-resistance to both TB and HIV looms if there is not urgent attention paid to the coinfection issue.

New research presented at the conference included both promising and disturbing results, the latter focusing

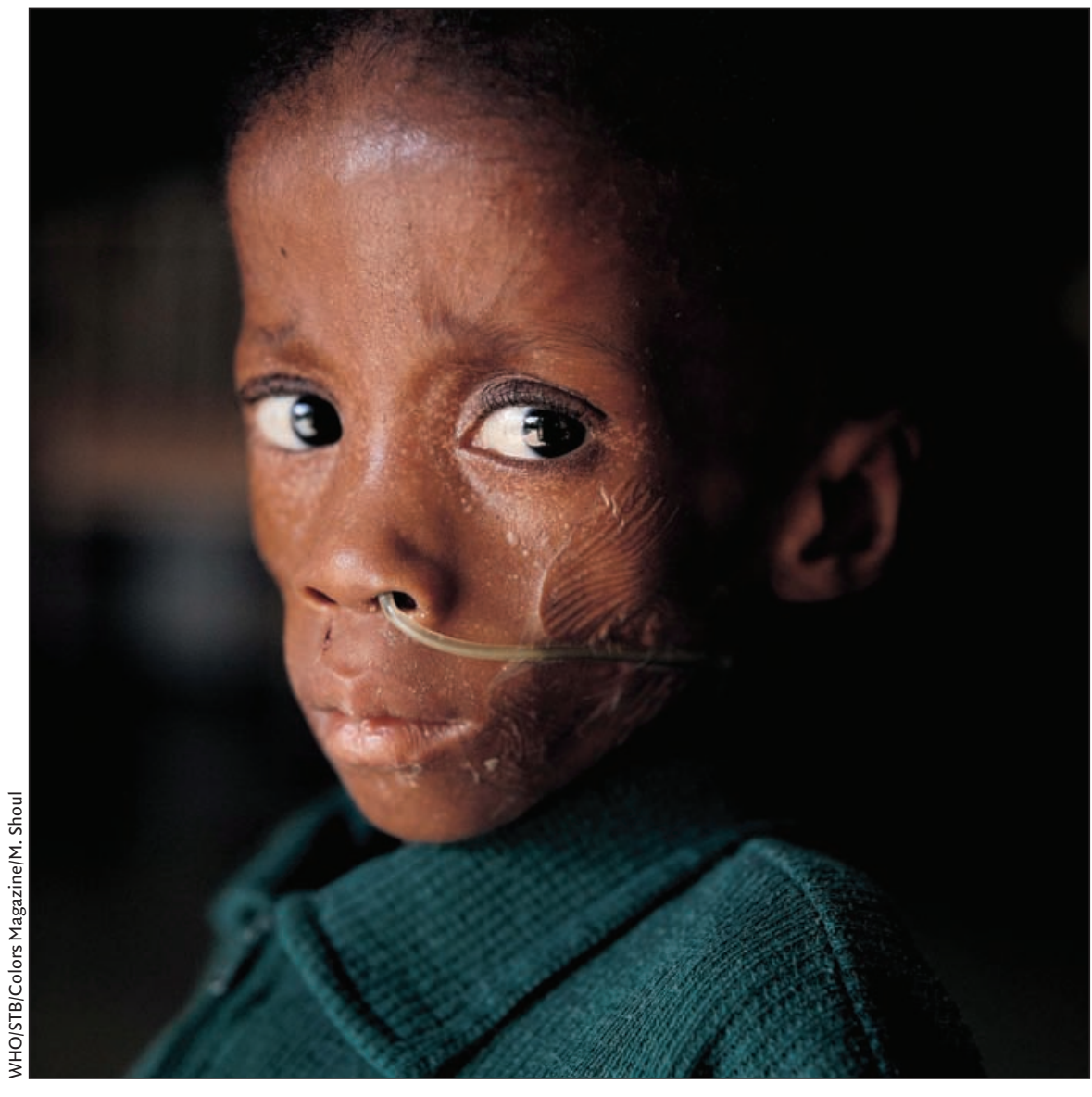

The face of HIV/TB: Vuyolwethu Tshambuluku, 8, is a patient at St. Joseph's Home for Chronic Invalid Children, Cape Town, South Africa.

on the emergence of TB strains, called XDR-TB, in South Africa that are resistant to both first- and second-line drugs.

People with HIV have an "exquisite vulnerability" to TB because of their weakened immune systems, De Cock noted. Among HIV-positive people with latent $\mathrm{TB}$, the chance of developing active TB increases by 6 times in the first year after HIV infection, and continues to increase over the years. When someone living with HIV develops active TB, the likelihood of progressing to full-blown AIDS increases by roo times.

Chesire told conference participants that she had been infected with HIV for Io years and was managing well. "But getting $\mathrm{TB}$ took me almost to my deathbed ... I had 3 surgeries and spent 7 months in a hospital bed."

Yet TB is preventable. A 6-month course of isoniazid preventive therapy, which has been around for 20 years, costs just pennies and is highly effective, says Dr. Richard Chaisson, a professor of medicine, epidemiology and international health at Johns Hopkins University and the principal investigator with CREATE, the Consortium to Respond Effectively to the AIDS/TB epidemic. CREATE was funded by the Bill and Melinda Gates Foundation and launched by Nelson Mandela at the XVth International AIDS conference in Bangkok 2 years ago.

People living with HIV face a $4 \%$ annual risk of developing active TB, Chaisson said. But prescribing isoniazid is a 
"tough sell, perhaps because there is an emphasis on treatment but not prevention," Chaisson told a press conference. "There seems to be a fear of developing resistance and of toxicity, but these are not warranted. Isoniazid has been studied perhaps more than any other treatment in medicine."

TB prevention, diagnostic and treatment services must become core functions of all HIV services in countries with a high prevalence of TB, De Cock said. People with HIV need to be screened for TB and get prophylaxis and people with TB need to be screened for HIV: "We need one-stop shopping." — Ann Silversides, Toronto

DOI:I0.I503/cmaj.o6II22

\section{Microbicide update}

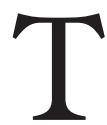
he US\$62-billion Bill and Melinda Gates Foundation has poured money into microbicide research, because a woman "should never need her partner's permission to save her own life," Bill Gates told the opening session of the XVIth International AIDS Conference in August.

Microbicides are applied to the vaginal or rectal surface before sex in order to prevent HIV infection. Microbicide research began in the early I99os, but it did not receive a great deal of funding or attention until a few years ago after the establishment of the non-profit International Partnership for Microbicides in 2002 brought new energy to the field.

There are now 5 gels, which must be applied immediately before sex, in phase 3 clinical trials. The products in earlier stages of development use direct antiretroviral effects. For example, a gel form of the drug tenofovir is in phase 2 trials.

A long-term goal is to develop a formulation or device that allows for the slow release of microbicide over a period of days or months. However, researchers are concerned that limited clinical trial capacity in countries with high rates of HIV infection is hampering advances. - Ann Silversides, Toronto

\section{Canada falters on promise}

\section{of AIDS drugs for Africa}

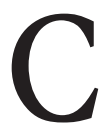

anada will immediately review the federal legislation intended to facilitate the timely production and export of affordable, life-saving drugs to the developing world, pledged federal Health Minister Tony Clement at the XVIth International AIDS Conference in Toronto.

The legislation, introduced more than 2 years ago by the former Liberal government, has come under fire because no drugs have been shipped from Canada.

Apotex, the Canadian generic company that stepped forward and developed a triple-combination HIV/AIDS drug for export, has been frustrated by the lengthy process. But company officials say they are more optimistic now that the World Health Organization has given the drug its stamp of approval.

The WHO prequalification, which was granted just before the AIDS conference began in August, gives developing world countries "a sense of security [that] now they can make a free choice" to seek to import the Apotex drug, explained Bruce Clark, vice-president of regulatory affairs.

Canada received kudos as the first country to pass legislation allowing its generic drug manufacturers to produce copies of patented medicines to be shipped to those who need them.

The vast majority of HIV/AIDS drugs now used in the developing world are manufactured by generic drug companies in countries that, until recently, did not have to comply with international patent rules. India, for example, supplies a significant proportion of HIV/AIDS drugs under the Global Fund. It passed legislation last year to comply with the patent rules, but can still produce copies of AIDS drugs patented in the earlier years of the epidemic.

The Canadian legislation became possible as a result of a provision adopted 3 years ago by the World Trade Organization, whose members agreed that the health needs of people in the developing world should take precedence over international patent agreements.

With the non-governmental organization Médecins Sans Frontières agree-

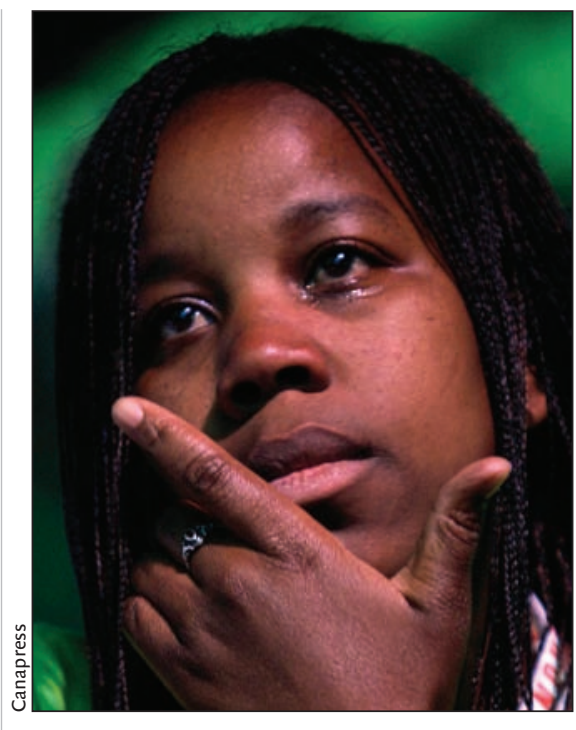

Thouands of people gathered for an AIDS vigil in Toronto on Aug. 17.

ing to act as "broker," Apotex developed a 3 -in-I drug for which there is no brand name equivalent. The drug combines ziduvodine (AZT), lamivudine (3TC) and nevirapine.

However, the Apotex drug has not yet been exported. The company says it is hung up in negotiations to obtain voluntary licences from the 3 patent-holding pharmaceutical companies involved. Such negotiations must take place, and be unsuccessful, before generic companies become eligible under the law to apply for compulsory licences.

As part of its application for a compulsory licence, Canadian law also requires generic companies to identify the developing country that is the intended recipient of a shipment. To date no country has publicly come forward to request the drug. Apotex's Clark attributes that reluctance to a country wondering "why should they be required to identify themselves in someone else's process." But the WHO pre-qualification should make countries more willing to come forward, he said, and Apotex is preparing its compulsory licence application.

Meanwhile, Anil Soni of the Clinton Foundation said he would be "thrilled" to see Canada issue a compulsory licence to export copies of life-saving drugs. Soni noted that the Apotex price for the new combination drug - the company is charging only its cost - is one-third less than what is now being 